\title{
A resolução de problemas no ensino de ciências baseada em uma abordagem investigativa
}

Elizete Terezinha da Silva elizetetsilva18@gmail.com orcid.org/0000-0002-4798-2190 Universidade Federal de Pernambuco (UFPE), Caruaru, Pernambuco, Brasil.

Roberto Araújo Sá

sa aaraujo@yahoo.com.br

orcid.org/0000-0003-1895-9175

Universidade Federal de Pernambuco (UFPE), Caruaru, Pernambuco, Brasil.

Veronica Tavares Santos Batinga veratsb@gmail.com

orcid.org/ 0000-0002-9660-396X

Universidade Federal Rural de

Pernambuco, Brasil

\section{RESUMO}

Este trabalho é parte de uma pesquisa mais ampla de mestrado acadêmico, que tem por objetivo avaliar as potencialidades de uma sequência didática sobre o tema Água elaborada com base na abordagem de Resolução de Problemas no contexto do Ensino por Investigação. A pesquisa foi realizada em uma turma de 9o ano do Ensino Fundamental II de uma escola pública de São Caetano, Pernambuco, na disciplina de Ciências. A coleta de dados constou da observação participante e as produções dos alunos na resolução dos problemas e atividades realizadas durante o desenvolvimento da sequência. Os dados foram analisados com base na trajetória dos alunos no processo de aprendizagem e de elementos presentes no ensino por investigação. Os resultados apontam que as atividades estruturadas para a sequência propiciou aos alunos o processo de busca do conhecimento e o desenvolvimento de habilidades, como: elaboração de hipóteses, planejamento de experimento, discussão e comunicação de ideias, trabalho em grupo, autonomia e resolução de problemas. Destaca-se também a identificação das dimensões epistêmica e pedagógica do conhecimento durante as ações desenvolvidas pelos alunos nas atividades da sequência. A abordagem dos conteúdos de Ciências no contexto da temática Água proporcionou a construção de conceitos químicos pelos alunos, de forma significativa, durante as atividades vivenciadas na sequência.

PALAVRAS-CHAVE: Resolução de Problemas. Ensino por Investigação. Ciências. Ensino Fundamental II. Água. 


\section{INTRODUÇÃO}

O ensino de ciências tem passado por diversas modificações ao longo dos últimos anos, com o objetivo de acompanhar as mudanças que a sociedade vem enfrentando. Nesse contexto, diferentes abordagens didáticas têm sido desenvolvidas com a finalidade de que os estudantes criem uma visão mais contemporânea da Ciência. A abordagem dos conhecimentos científicos como um processo em construção e contextual, e não como um produto acabado, pode favorecer aos alunos que se tornem participantes ativos do processo de aprendizagem, uma vez que nesta abordagem a relação que o sujeito mantém com o mundo e suas vivências pode influenciar na apropriação de novos significados e estimular a busca pelo aprendizado (SOLINO; FERRAZ; SASSERON, 2015).

No contexto atual, o ensino de ciências deve fazer sentido para o aluno e ajudá-lo não apenas a compreender o mundo físico, mas a reconhecer seu papel como participante de decisões individuais e coletivas na sociedade. Um dos objetivos do ensino de ciências é fazer com que os estudantes se apropriem do conhecimento científico e passem a compreender a Ciência como uma construção social e humana. No entanto, grande parte das instituições escolares ainda privilegiam abordagens de ensino voltadas para a transmissão, memorização e reprodução dos conteúdos, favorecendo a passividade dos estudantes durante o processo de ensino e aprendizagem (BRASIL, 1997; DIAS, 2016).

Nessa perspectiva, Schnetzler e Aragão (1995) definem o ensino por transmissão-recepção como sendo

\footnotetext{
Uma prática de ensino encaminhada quase exclusivamente para a retenção, por parte do aluno, de enormes quantidades de informações passivas, como propósito de que essas sejam memorizadas, evocadas e devolvidas nos mesmos termos em que foram apresentadas na hora dos exames, através das provas, testes e exercícios mecânicos repetitivos (SCHNETZLER; ARAGÃO, 1995 p. 27).
}

Nesse cenário, surge a necessidade de desenvolver propostas de ensino de ciências que possibilitem aos estudantes resolver problemas relacionados com o conhecimento científico escolar a partir de temas ou situações reais que fazem parte do contexto no qual eles estão inseridos. No processo de resolução de problemas, na perspectiva investigativa, os estudantes têm a possibilidade de desenvolver o pensamento crítico, atividades investigativas e a tomada de decisão sobre questões que envolvem o conteúdo de ciências, relacionando-o com aspectos da Tecnologia, Sociedade e Ambiente (MOREIRA; PEDRANCINI, 2016).

Diante do exposto, este trabalho objetiva avaliar as potencialidades das atividades propostas numa sequência de ensino e aprendizagem ou sequência didática (SD) sobre a temática Água, elaborada com base na abordagem de Resolução de Problemas, visando contribuir para a construção de alguns conceitos de ciências no Ensino Fundamental II.

O tema Água se mostra relevante diante dos problemas atuais enfrentados pela sociedade, como escassez de água e a necessidade de conservação dos recursos hídricos, o que sugere a importância de uma mudança de postura dos indivíduos e da população sobre essas questões, buscando a garantia da própria sobrevivência. Esse tema também potencializa a contextualização do processo de 
ensino e aprendizagem de Ciências, principalmente quando se busca articular o conhecimento científico escolar com problemas reais que emergem da sociedade.

\section{O ENSINO DE CIÊNCIAS NO ENSINO FUNDAMENTAL}

A disciplina de ciências no Ensino Fundamental aborda conhecimentos que são imprescindíveis à formação e ao desenvolvimento do aluno, pois são conteúdos relacionados com o estudo dos fenômenos e eventos da natureza, do universo, dos seres vivos e da matéria. Os conteúdos abordados referem-se à diferentes áreas do conhecimento, tais como Biologia, Química, Física e Geociências. Tradicionalmente, estes conhecimentos são apresentados nos livros didáticos de maneira fragmentada. O programa escolar do nono ano do Ensino Fundamental, por exemplo, é composto, geralmente, por conteúdos de Química e Física que são desenvolvidos como se fossem disciplinas separadas e desconexas (MILARÉ; ALVES FILHO, 2010; GRAMOWSKI et al., 2004).

Assim, notamos que normalmente o componente curricular de ciências não é bem aceito pelos alunos, sendo considerado chato, de difícil compreensão e até mesmo sem importância, pois não possibilita uma visão crítica e reflexiva do aluno e do mundo ao seu redor (LIMA et al., 2016).

Nas orientações e concepções apresentadas nos documentos oficiais, sendo eles: a Lei de Diretrizes e Bases da Educação Nacional (BRASIL, 1996), as Diretrizes Curriculares Nacionais (BRASIL, 2010) e os Parâmetros Curriculares Nacionais (BRASIL, 1998), observa-se que há um consenso sobre a necessidade de uma organização dos conteúdos no ensino de ciências, de forma a abandonar a proposta fragmentada e buscar uma articulação entre os diversos conhecimentos das suas diferentes áreas, para um melhor entendimento dos fenômenos naturais pelos estudantes (GRAMOWSKI et al., 2004).

Nesse contexto, Chassot (2003, p. 91) defende que a alfabetização científica deve ser considerada uma das dimensões para fomentar alternativas que privilegiem uma educação mais comprometida. Conforme assinala o autor, entender a Ciência nos permite, também, controlar e prever as transformações que ocorrem na natureza. Dessa forma, poderemos fazer com que essas transformações sejam conduzidas de forma a proporcionar uma melhor qualidade de vida aos indivíduos.

Ainda segundo esse autor, a alfabetização científica só pode ocorrer quando a escola, em todos os níveis de ensino, cumprir com o seu papel de instrumentalizar os indivíduos para que saibam utilizar os conhecimentos científicos adquiridos para resolver problemas do cotidiano e tomar decisões responsáveis, reconhecendo que a Ciência e suas produções tanto podem contribuir para a melhoria das condições de vida da população, quanto podem trazer consequências negativas para o ser humano e o seu meio (CHASSOT, 2003, p. 91).

Dessa forma, para introduzir a alfabetização científica e romper com a fragmentação dos conteúdos que dificulta a aprendizagem e distancia a Ciência da vivência dos alunos, é necessário um processo de ensino e aprendizagem que privilegie pequenas investigações, atividades, ações, interações e questionamentos na sala de aula, bem como estudos sobre as interações entre 
ciência, tecnologia e sociedade a partir de temas sociocientíficos (MUNFORD; LIMA, 2007).

\title{
ENSINO DE CIÊNCIAS POR INVESTIGAÇÃO
}

De acordo com Abreu (2008), o ensino com base na investigação e na resolução de problemas é uma das abordagens didáticas que podem contribuir para a alfabetização científica no contexto escolar. Entretanto, para que essas abordagens alcancem o objetivo esperado é necessário que os alunos tenham consciência do que estão aprendendo.

Nessa perspectiva, Suart (2008) define uma abordagem investigativa como:

\begin{abstract}
Aquelas atividades nas quais os alunos não são meros espectadores e receptores de conceitos, teorias e soluções prontas. Pelo contrário, os alunos participam da resolução de um problema proposto pelo professor ou por eles mesmos; elaboram hipóteses; coletam dados e os analisam; elaboram conclusões e comunicam os seus resultados com os colegas. O professor se torna um questionador, conduzindo perguntas e propondo desafios aos alunos para que estes possam levantar suas próprias hipóteses e propor possíveis soluções para o problema (STUART, 2008, p. 27).
\end{abstract}

Segundo Carvalho (2018), o ensino por investigação é compreendido como o ensino dos conteúdos, no qual o professor propõe para os alunos as seguintes condições em sala de aula: pensar, considerando a estrutura do conhecimento; falar, evidenciando seus argumentos e conhecimentos construídos; ler, entendendo criticamente o conteúdo lido; escrever, mostrando autoria e clareza nas ideias expostas. Sasseron (2018) destaca cinco elementos presentes no ensino por investigação, tais como: o papel intelectual e ativo dos estudantes; a aprendizagem para além dos conteúdos conceituais; o ensino por meio da apresentação de novas culturas aos estudantes; a construção de relações entre práticas cotidianas e práticas para o ensino; a aprendizagem para a mudança social. Assim, observa-se que é necessária uma mudança de papel tanto do aluno quanto do professor, o qual passa de detentor do conhecimento para mediador.

Corroborando com este entendimento, Carvalho (2013) afirma que o ensino de Ciências por investigação tem como objetivo criar um ambiente investigativo na sala de aula, de modo que o ensino vise conduzir e mediar os alunos no processo simplificado do trabalho científico para que eles possam gradualmente ir desenvolvendo a cultura científica no espaço escolar. Nesse sentido, as aulas devem ser planejadas de maneira a proporcionar condições para que os alunos expressem seus conhecimentos prévios para iniciar a construção dos novos, apresentando ideias próprias e discutindo-as com seus colegas e com o professor. Dessa maneira, os alunos partem gradativamente do conhecimento cotidiano para o conhecimento científico escolar, adquirindo condições para compreenderem os conhecimentos já estruturados por gerações anteriores.

Ensinar por investigação significa fazer uma aproximação dos conhecimentos científicos com os conhecimentos escolares, mobilizando a ação do aluno nas atividades propostas em sala de aula (VIEIRA, 2012). Nesse viés, esse modelo de ensino surge, no contexto desse trabalho, como uma proposta que contempla o objetivo atual da educação básica voltada para a formação de cidadãos. De acordo 
com Sasseron (2018), o ensino por investigação é uma abordagem didática que associa às ações e às práticas realizadas pelo professor para a proposição de estratégias e atividades aos alunos, sendo necessária a autonomia intelectual dos estudantes para a investigação de problemas (CARVALHO, 2013). Nessa direção, esta abordagem didática é focada no aluno e tem como finalidade a aprendizagem por meio da introdução e resolução de problemas ou enigmas que estimulem o desenvolvimento de habilidades conceituais, procedimentais e atitudinais nas diversas áreas do conhecimento.

\section{A ABORDAGEM DE RESOLUÇÃO DE PROBLEMAS (ARP)}

A ARP é considerada uma metodologia de ensino e aprendizagem centrada no aluno que estimula o desenvolvimento de suas habilidades para conduzir e participar de atividades de pesquisa, integrando os conhecimentos teóricos e práticos, além da aplicação de estratégias e conhecimentos para desenvolver uma solução viável para um determinado problema (LOPES et al., 2011; AMADO, 2015; BATINGA; TEIXEIRA, 2014).

A ARP se situa no contexto e engloba características do ensino por investigação, tendo como objetivo desenvolver a autonomia dos alunos e a aprendizagem de conteúdos conceituais, procedimentais e atitudinais. Para isso, parte dos conhecimentos pré-existentes dos alunos durante o processo de resolução de problemas.

A resolução de problemas (RP) baseia-se na apresentação e resolução de problemas reais ou fictícios (BATINGA; TEIXEIRA, 2014) que exigem dos alunos uma atitude ativa e um esforço para encontrar respostas adequadas ao contexto dos problemas a ser resolvidos. Nesse sentido a RP visa ensinar os alunos a resolver diferentes problemas, e nesse processo eles aprendem conteúdos teóricos e práticos inerentes à resolução dos problemas propostos em diversas áreas do conhecimento (GOI; SANTOS, 2003). Segundo Pozo (1998), ensinar os alunos a resolver problemas significa torná-los aptos a encontrarem por si mesmos respostas às perguntas que eles precisam responder, ao invés de esperar uma resposta já elaborada por outros e transmitida pelo livro-texto ou pelo professor.

A resolução de problemas pode ser compreendida como uma estratégia de ensino e aprendizagem que considera os aspectos relativos à vivência de um contexto conhecido pelos alunos na proposição e no processo de resolução de problemas. Isso promove uma maior aproximação dos problemas postos, em especial nas aulas de Ciências e Química, com a realidade dos alunos em seu cotidiano e com os problemas reais que a sociedade enfrenta (BATINGA; TEIXEIRA, 2014).

A palavra problema pode ser associada a diferentes significados, entretanto, muitas vezes no contexto escolar não se faz uma distinção clara entre exercício e problema. Para abordar a Resolução de Problemas na sala de aula, é fundamental deixar claro a diferença entre esses dois termos. O exercício pode ser solucionado de forma imediata utilizando mecanismos que levam à resposta, priorizando a memorização de regras, equações e fórmulas. Os exercícios são solucionados com base no uso de técnicas e habilidades já aprendidas que, em consequência da 
prática, se transformam em uma rotina (LOPES, 1994; POZO, 1998; BATINGA; TEIXEIRA, 2014).

Para Leite e Esteves (2005), problema é um enunciado que apresenta um obstáculo a ser solucionado, sem uma fórmula a ser seguida, e que pode ter mais de uma solução possível ou não ter solução. D'Ambrósio (2010, p. 1) afirma que "problema é uma situação, real ou abstrata, ainda não resolvida, em qualquer campo do conhecimento e de ação". Pozo (1998) define problema como uma situação na qual não dispomos de procedimentos automáticos que permitam solucioná-la de forma imediata, sem exigir, de alguma forma, a reflexão ou tomada de decisão sobre os passos a serem seguidos para chegar a solução. Há entre esses autores a ideia de que problema é uma situação para a qual não se possui os conhecimentos necessários para solucionar de forma imediata, exigindo uma atitude do aluno para superar esse obstáculo. Para Goi e Santos (2003), problemas são desafios dotados de características que instigam a capacidade de raciocínio, e também que põem à prova a capacidade de criar, de decodificar informações, de relacionar e planejar procedimentos adequados para a sua resolução.

\section{A TEMÁTICA ÁGUA NO ENSINO DE CIÊNCIAS NO ENSINO FUNDAMENTAL II}

A água é um recurso natural essencial para a sobrevivência dos seres vivos, precisamos dela para diversas atividades do nosso dia a dia, como: cozinhar alimentos, saciar nossa sede, higienização de nosso corpo, para limpeza doméstica, dentre outras atividades. Entretanto, a água sem tratamento adequado pode causar diversas doenças, pois pode possuir substâncias químicas (agrotóxicos) ou microrganismos (bactérias, vírus e protozoários) que causam doenças. As principais doenças causadas por água contaminada são: cólera, hepatite $A$, leptospirose, amebíase, febre tifoide e esquistossomose. Além disso, existem doenças que são transmitidas por insetos que nascem na água ou que picam próximos a fontes de água. Dentre essas doenças, podemos destacar a dengue, a febre amarela e a malária. Sendo a água tão importante para nossa vida e estando esse recurso em risco no nosso planeta, constitui-se em um tema relevante e que permite trazer para o contexto os conceitos químicos e a formação de um pensamento crítico e reflexivo (DIAS, 2016).

De acordo com Gozer (2012), o tema água é considerado importante no ensino de ciências, pois permite problematizar situações da realidade do aluno. Assim, deve estar presente no contexto educacional, com enfoque na ética e na formação do cidadão consciente do lugar que ocupa no mundo, que parte do local e se relaciona com o global. Os PCN de Ciências Naturais também abordam a necessidade de trabalhar a importância dos recursos hídricos para os seres vivos, envolvendo assuntos como: formas de aproveitamento da água; o desperdício; a reutilização; a qualidade; o tratamento e a distribuição da água e os processos vitais mais importantes dos quais a água faz parte (BRASIL, 1998).

A água normalmente aparece nos programas de Química quando são tratados conteúdos como separação de misturas, substância pura, ligações químicas, soluções, forças intermoleculares, polaridade, geometria e ácidos/bases. Entretanto, devido à forma como esses conteúdos são abordados - por meio de um ensino voltado para transmissão-recepção - os alunos não conseguem associar a água trabalhada na aula com a água do seu dia a dia (QUADROS, 2004). 
De acordo com Torralbo (2009), existem diversas propostas de ensino de Química a partir do tema água, porém, a autora chama a atenção para a forma como esse tema é abordado, pois, muitas vezes, a temática água fica em segundo plano, servindo apenas para motivar os alunos e para descrição ou exemplificação de conceitos químicos. Além disso, Quadros (2004) ressalta que algumas propostas de ensino com temáticas ambientais relacionam a Química com o cotidiano de maneira negativa, uma vez que muitos trabalhos referem-se à "poluição das águas", "destruição da camada de ozônio", "chuva ácida" e "efeito estufa", o que pode reforçar uma visão da Química como sendo apenas prejudicial ao ser humano e meio ambiente.

Diante do exposto, pretendemos abordar neste trabalho a temática Água, com o objetivo de introduzir o conteúdo de Matéria e suas transformações, previsto na disciplina de Ciências no 9o ano do Ensino Fundamental, contextualizando-o com as diversas tecnologias utilizadas para o tratamento de água. Além disso, buscamos trazer para a sala de aula o ensino de conceitos químicos e a reflexão de atitudes de conscientização e responsabilidade com relação à qualidade e uso da água, pretendendo contribuir na formação dos estudantes para que estes se tornem cidadãos ativamente engajados no desenvolvimento sustentável.

\section{METODOLOGIA}

Esta pesquisa é de caráter qualitativo, envolvendo um estudo de caso (LÜDKE; ANDRÉ, 1986). O objetivo deste trabalho centra-se na análise das potencialidades de uma sequência didática sobre o tema Água, elaborada com base na abordagem de Resolução de Problemas no contexto do Ensino por Investigação. Participaram da pesquisa 10 alunos do 9 ano do Ensino Fundamental II, de uma escola pública da cidade de São Caetano, interior de Pernambuco. O 9o ano foi escolhido para aplicação da sequência por ser o primeiro contato dos alunos com a Química na escola.

A seguir, apresentamos de forma detalhada os momentos e aulas que constituíram o desenho da sequência didática.

Aula 1: resolução inicial dos problemas. A aula consistiu na leitura e apresentação (pela pesquisadora) de dois problemas, denominados P1 e P2, para serem resolvidos pelos estudantes. Essa atividade objetivou analisar as concepções prévias dos estudantes sobre os conteúdos de Ciências associados à temática Água, dentre eles: composição da água, estados físicos da matéria e tratamento da água. A resolução dos problemas foi feita de modo individual e não foi permitida a consulta a nenhum material didático. $O$ instrumento de coleta de dados utilizado nessa aula foi uma ficha que constou dos enunciados de P1 e P2 (Quadro 1).

Do ponto de vista da conceituação do termo problema, os enunciados (P1 e P2) elaborados pela professora e propostos à turma se configuram como problemas segundo Pozo (1998), quando afirma que: problema é uma situação na qual não se dispõe de conhecimentos e procedimentos necessários que permitam solucioná-la de forma imediata, por isso, exige-se dos alunos uma atitude para superar obstáculos na busca de sua resolução. 
Quadro 1 - Ficha com Problemas

\begin{tabular}{|l|l|}
\hline Sabe-se que cerca de 71\% da superfície da Terra é coberta por \\
água. Porém, mesmo diante de tanta água em nosso planeta, \\
corremos o risco de ficarmos sem água potável para o consumo. \\
Para ser considerada potável, a água tem que atender a \\
determinados requisitos quanto à sua natureza física, química e \\
biológica. Assim, depois de captada dos rios, barragens ou poços, \\
a água é levada para a estação de tratamento, onde passa por \\
várias etapas, depois é distribuída para a população. Considerando \\
essas informações, responda: \\
P1 $\quad$ Questionamento 1: Você acha que a água que sai da sua \\
torneira pode ser consumida sem nenhum outro tratamento? \\
Justifique sua resposta. \\
- Questionamento 2: A simples aparência física da água é \\
suficiente para garantir sua potabilidade? Ou apenas por processo \\
de separação de mistura (filtração) é possível alcançar esta \\
potabilidade? Por quê?
\end{tabular}
Fonte: autoria própria (2018).

Aula 2: Debate sobre escassez e contaminação da Água: foram utilizados os vídeos: 1. "Poluição do Rio Ipojuca", disponível no YouTube e 2. "A Química no tratamento da Água", também disponível no YouTube. Após a exibição de cada vídeo, deu-se início a uma atividade de debate sobre os aspectos abordados. Nesse momento, os alunos foram organizados em círculos, de forma que todos puderam interagir durante as discussões com a mediação da professora. Nesta ocasião, o instrumento de coleta de dados utilizado foi a observação participante, a partir de anotações das interações e discussões ocorridas entre a turma pela professora.

Aulas 3 e 4: aulas expositivas dialogadas. Nessa atividade a professora abordou a definição das misturas homogêneas e heterogêneas e seus diferentes métodos de separação, bem como a conceituação e diferenças entre fenômenos físicos e químicos. Para tal, ela utilizou como recursos didáticos slides e imagens projetados pelo datashow. Ao final das aulas, os estudantes se organizaram em grupos para preparar/planejar uma atividade experimental. Para isso, eles usaram amostras de água e outros materiais para preparar misturas, e em seguida apresentar a turma os diferentes métodos de separação dos componentes de uma mistura. Nessas aulas, foi usada a observação participante como instrumento de coleta de dados, que constou do registro de falas/participação dos estudantes em alguns episódios durante a apresentação dos experimentos.

Aula 5: realização de uma atividade experimental planejada pelos alunos. A aula consistiu na simulação de etapas do tratamento da água associado aos métodos de separação de misturas. Foram utilizadas amostras de água misturada 
com diferentes materiais (óleo, sal, areia, detergente etc.). Essa atividade foi realizada em grupos de três alunos, com mediação da professora. Os instrumentos de coletas de dados utilizados foram a observação participante, os registros de participação, fotografias e resolução de questões pelos alunos durante a execução da tarefa.

Aula 6: reapresentação dos problemas aos estudantes. Nessa atividade, os alunos responderam novamente aos problemas P1 e P2 de forma individual e sem consulta a qualquer material didático, tecnológico ou aos colegas. Nesse momento, o instrumento de coleta de dados utilizado foi uma ficha (Quadro 1) com o registro das respostas dos estudantes para a resolução dos problemas.

\section{ANÁLISE DOS DADOS}

Para análise dos dados, visando alcançar o objetivo de pesquisa, foram adotados os seguintes critérios: a) Identificação das dimensões epistêmica e pedagógica presentes nas ações realizadas pelos alunos e professor nas atividades da sequência. A epistêmica considera a construção do conhecimento como uma ação voltada para interpretação do mundo, compreensão de métodos científicos e comprovação de hipóteses. E a pedagógica consiste das interações diversas que ocorrem entre professor e alunos e alunos-alunos (MÉHEUT, 2005); b) Validação interna da sequência tomando por base ideias de Méheut (2005) e nas características do Ensino por Investigação (SUART, 2008). A validação interna refere-se à análise das informações sobre a trajetória de aprendizagem dos alunos nas atividades da sequência (MÉHEUT, 2005).

Para analisar a trajetória de aprendizagem foram estabelecidas algumas categorias relacionadas com as respostas dos alunos na resolução dos problemas P1 e P2 (aulas 1 e 6) (Quadro 2) e nas ações realizadas pelos alunos nas atividades desenvolvidas na sequência como: exibição de vídeos e debate, aula expositiva dialogada, atividade experimental e resolução de questões (aulas 2, 3, 4 e 5) na vivência da abordagem da resolução de problemas no contexto do ensino por investigação.

Quadro 2 - Categorias de análise das respostas dos alunos aos problemas propostos

\begin{tabular}{|c|c|c|}
\hline & Categoria & Critério \\
\hline \multirow{3}{*}{ P1 } & Resposta Satisfatória (RS) & $\begin{array}{l}\text { Consideramos uma resposta satisfatória quando o } \\
\text { aluno explicou com base no conhecimento científico } \\
\text { escolar as características da água potável, seus } \\
\text { estados físicos, hábitos de consumo do ser humano } \\
\text { e os métodos de separação de mistura. }\end{array}$ \\
\hline & Resposta Insatisfatória (RI) & $\begin{array}{l}\text { Consideramos uma resposta insatisfatória quando o } \\
\text { aluno não faz relação entre as caraterísticas da água } \\
\text { e sua adequação para o consumo humano. }\end{array}$ \\
\hline & Não Respondeu (NR) & $\begin{array}{c}\text { Classificamos como “não respondeu” quando os } \\
\text { alunos deixavam a questão em branco, sem } \\
\text { resposta. }\end{array}$ \\
\hline $\mathrm{P} 2$ & Resposta Satisfatória (RS) & $\begin{array}{l}\text { Consideramos resposta satisfatória quando o aluno } \\
\text { cria uma estratégia para solucionar o problema, } \\
\text { levando em consideração as propriedades da água } \\
\text { como solvente universal. }\end{array}$ \\
\hline
\end{tabular}




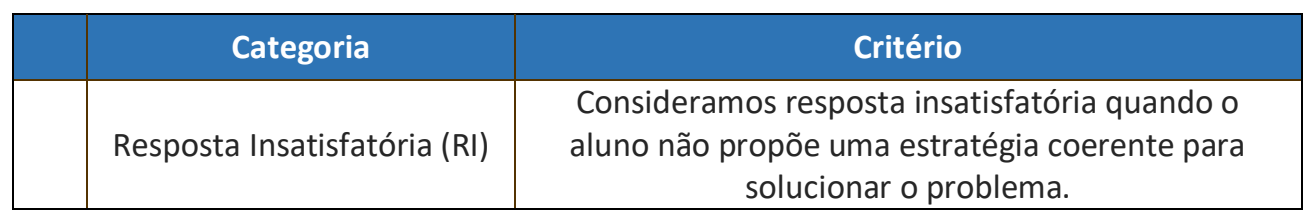

Fonte: autoria própria (2018).

\section{RESULTADOS E DISCUSSÃO}

\section{VALIDAÇÃO INTERNA DA SEQUÊNCIA DIDÁTICA SOBRE A ÁGUA}

\section{ANÁLISE DAS CONCEPÇÕES DOS ALUNOS RELATIVAS A ASPECTOS DO TEMA ÁGUA}

Apresentamos a análise das concepções prévias dos estudantes (1a aula) com base em suas respostas iniciais a P1 (Quadro 1).

P1. Sabe-se que cerca de $71 \%$ da superfície da Terra é coberta por água. Porém, mesmo diante de tanta água em nosso planeta corremos o risco de ficarmos sem água potável para o consumo. Para ser considerada potável, a água tem que atender a determinados requisitos quanto a sua natureza física, química e biológica. Assim, depois de captada dos rios, barragens ou poços, a água é levada para a estação de tratamento, onde passa por várias etapas de tratamento e depois é distribuída para a população. Considerando essas informações responda:

Questionamento 1: você acha que a água que sai da sua torneira pode ser consumida sem nenhum outro tratamento? Justifique sua resposta.

De acordo com análise das respostas dos alunos ao 10 questionamento percebemos que a maioria dos alunos (8) reconheceu que não se pode consumir a água da torneira sem fazer outro tratamento. Apenas o aluno $\mathrm{A} 1(10 \%)$ apresentou justificativa de acordo com o esperado para a categoria de resposta satisfatória (RS). A1 respondeu da seguinte forma: "não, porque ainda pode ter bactérias presentes na água, por isso precisa fazer outros tratamentos como filtrar ou ferver a água antes de consumi-la". Sete alunos (70\%) apresentaram respostas com justificativa incoerente, por exemplo, o aluno A5: "não, porque mesmo assim há de ter mais tratamento", que se enquadraram na categoria RI. Dois alunos (20\%) não responderam (NR). Apresentamos a análise das concepções prévias dos estudantes ( 1 a aula) com base em suas respostas iniciais ao $2 \cong$ questionamento de P1.

Questionamento 2 (P1): a simples aparência física da Água é suficiente para garantir sua potabilidade? Ou apenas por processo de separação de mistura (filtração) é possível alcançar esta potabilidade? Por quê?

Com relação ao segundo questionamento, a análise indicou que todos os alunos responderam que a aparência física não é suficiente para garantir a potabilidade da água. Apenas dois alunos (20\%) expressaram justificativas que se enquadram na categoria (RS) para esta questão, como o aluno A3, por exemplo, que respondeu: "não, porque mesmo a água parecendo estar limpa ainda pode conter bactérias presentes na água que não conseguimos ver a olho nu. Além disso, 
é preciso analisar o cheiro e o gosto". Oito alunos (80\%) apresentaram RI, como o aluno A6, por exemplo: "não, porque a água precisa passar por outras etapas para ficar limpa".

Apresentamos a análise das concepções prévias dos estudantes (1a aula) com base em suas respostas iniciais a P2 (Quadro 1) a seguir:

P2: O rio Ipojuca em outras épocas servia como incentivo ao turismo e era referência de lazer e pesca para moradores da região. Atualmente o Ipojuca é o terceiro rio mais poluído do Brasil (SOUSA, 2017). Considerando essas informações, responda: Questionamento 1: O que você faria para solucionar o problema do rio Ipojuca? o objetivo foi levar os alunos a refletir sobre a poluição do Rio Ipojuca e propor uma solução para resolver o problema desse rio, levando em consideração as propriedades da água e métodos de despoluição.

A análise das respostas ao questionamento 1 (P2) mostrou que: nenhum aluno respondeu de forma satisfatória. Todos os alunos (100\%) responderam que a situação seria resolvida apenas proibindo de se jogar lixo no rio. A título de ilustração, o aluno A6 afirmou que: "proibiria de jogar lixo e esgotos no rio". Esse resultado está de acordo com pesquisa realizada por Fernandes (2015), a qual aponta que os alunos têm consciência das ações humanas que contribuem para a poluição dos rios, mas não têm conhecimento sobre métodos de despoluição dos recursos hídricos.

No 2ㅇ questionamento: por que é tão comum a água ficar contaminada? nove alunos não apresentaram respostas satisfatórias que levassem em consideração as propriedades químicas da água, como se mostra evidente na resposta do aluno A7: "Por conta dos lixos jogados pela população e esgotos". Um aluno não respondeu a esse questionamento (NR). A maioria (9) tem a ideia de que a água fica contaminada por causa do descarte de lixos e esgotos.

Para o questionamento 3 sobre "o que polui o rio", todos os alunos responderam que são os lixos e esgotos que poluem o rio. As respostas foram comiseradas satisfatórias (RS) visto que apesar de ser uma resposta simplificada, a mesma está de acordo com a situação atual e aparente do rio Ipojuca, representando uma visão de poluição do senso comum, baseada nos conhecimentos e experiências advindas do cotidiano dos alunos.

\section{ANÁLISE DAS AÇÕES DOS ALUNOS NAS ATIVIDADES DA SEQUÊNCIA DIDÁTICA}

As ações desenvolvidas pelos alunos durante a realização das atividades da sequência se aproximam das que correspondem às propostas no ensino investigativo, de acordo com Suart (2008), Carvalho (2018), Sasseron (2018) e Vieira (2012), tais como: desempenho de papel ativo pelo aluno a partir da mobilização de seus conhecimentos prévios, elaboração de estratégias, delimitação dos problemas (P1 e P2) com base na interpretação de seus enunciados e formulação de hipóteses que correspondem a possíveis soluções iniciais no processo de resolução dos problemas.

Na segunda aula os estudantes assistiram a dois vídeos, que abordavam diferentes aspectos relacionados à poluição do rio Ipojuca e as diferentes etapas de tratamento de água. Ao final da exibição dos vídeos, a professora mediou o 
debate entre os estudantes sobre escassez, contaminação e tratamento da água. Observamos que muitas informações fornecidas nos vídeos e aprendidas pelos estudantes durante o debate contribuiu para elucidar algumas questões que emergiram nas suas respostas iniciais aos problemas. As trocas e interações ocorridas entre os alunos e a professora ao longo do debate proporcionou a reflexão deles sobre aspectos sociais, tecnológicos e históricos relacionados com a poluição das águas e para o uso inadequado desse recurso natural (SASSERON, 2018). Corroborando com Méheut (2005), as atividades de exibição de vídeo e debate contribuíram para a emergência da dimensão epistêmica pelo fato da abordagem dos conteúdos de química estar articulada ao contexto da temática Água e da pedagógica por permitir a interação entre alunos-alunos e alunosprofessora.

Nas aulas expositivas dialogadas ( 3 e 4) a professora abordou conceitos químicos relativos à temática água, tais como: substâncias, misturas e suas diferenças, processos de separação de misturas, propriedades da água e suas etapas de tratamento. Nesse momento foi possível perceber a emergência da dimensão pedagógica (MÉHEUT, 2005) por meio da participação dos alunos na discussão dos conceitos de química a partir de colocações, descrição de exemplos e esclarecimento de dúvidas, com a mediação da professora. A apropriação dos conhecimentos trabalhados nessas aulas pelos alunos contribuiu para 0 desenvolvimento das atividades seguintes da sequência.

A atividade (aula 5) permitiu analisar a capacidade dos alunos em planejar experimentos e associa-lo aos fenômenos que neles ocorrem com os conceitos químicos abordados nas aulas 3 e 4. Para discutir sobre os métodos de separação de misturas e as etapas do tratamento da água de forma contextualizada, os alunos prepararam misturas utilizando amostras de água e outras substâncias, as quais foram escolhidas por cada grupo. Em seguida, eles buscaram explicar os métodos adequados para separar os componentes de cada mistura (CARVALHO, 2018).

O grupo 1 realizou um experimento utilizando dois pratos contendo, em cada um, uma mistura de água e orégano. Em seguida, foi introduzido um dedo molhado com detergente na mistura (prato 1) e outro sem o detergente (prato 2). No dedo sem a presença do detergente não houve modificação (prato 2), mas com o uso de detergente ocorreu a repulsão do orégano na mistura (prato 1). 0 grupo 1 afirmou que escolheu esse experimento por achar muito interessante, parecer mágica. $\mathrm{Na}$ explicação desse fenômeno o grupo 1 afirmou que a água forma uma película e o detergente quebra tal película, causando a repulsão do orégano. Em seguida, a professora questionou o grupo acerca de qual método de separação eles usariam para separar os componentes dessa mistura, e partir disso, proporcionou uma discussão com a turma sobre este experimento. Esse resultado aponta que alguns alunos ainda têm uma visão da experimentação como magia. A respeito disso, autores como Gonçalves e Galiazzi, (2004) defendem que: se os alunos se motivam pela magia das atividades experimentais, cabe ao professor partir desse conhecimento inicial para problematizá-lo na direção da construção de conhecimentos mais consistentes que aproximem os estudantes do conhecimento científico escolar (GONÇALVES; GALIAZZI, 2004). Tal aspecto converge com a atitude de questionamento da professora ao grupo 1 (SUART, 2008).

O grupo 2 realizou um experimento utilizando água e sal como exemplo de uma mistura homogênea e água e areia exemplificando uma mistura heterogênea. 
Esse grupo explicou corretamente a diferença entre os tipos de misturas e os métodos de separação que poderiam ser utilizados, associando-os com os processos de tratamento da água (CARVALHO, 2018; SASSERON, 2018).

O grupo 3 realizou um experimento que simulou as etapas do tratamento da água, utilizando um filtro confeccionado com garrafa PET e com a adição de areia, algodão, água, folhas de árvores. A partir do experimento eles explicaram os processos de separação de misturas que acontecem no tratamento da água, como a filtração.

Ao final da apresentação dos experimentos pelos grupos, a professora solicitou-Ihes a resolução de cinco (Q1, Q2, Q3, Q4 e Q5) questões descritas a seguir.

A questão 1 (Q1) indagou: "a água coletada de uma fonte natural pode ser utilizada sem tratamento para consumo humano? Justifique sua resposta". Dois grupos (G1 e G2) responderam que a água poderia ser consumida sem tratamento porque era de fonte natural. Isto indica que eles entendem a expressão "fonte natural" como "sem contaminação", uma vez que essa associação foi explicitada nas respostas desses grupos. 0 grupo 3 respondeu que a água não poderia ser usada, destacando a presença de substâncias que podem afetar a saúde humana: "Não, porque ela (água) pode conter muitas impurezas que fazem mal a saúde".

Na segunda questão (Q2): "qual a função de cada etapa do tratamento da água?", as respostas dos grupos apontam que os alunos compreendem a função geral de uma estação de tratamento, como expresso na fala de G1: "eliminar as impurezas, tornar a água própria para o nosso consumo".

A terceira questão (Q3) indagou: "qual tipo de água você usa? Antes de usa-la você faz algum tratamento? Justifique sua resposta". Todos os grupos responderam que bebiam água mineral e não faziam nenhum tratamento porque esse tipo de água é próprio para o consumo humano. Para as outras atividades domésticas utilizavam a água potável da torneira.

A quarta questão (Q4) indagou: "por que devemos evitar o desperdício de água"? Essa questão objetivou verificar se os alunos tinham consciência da necessidade de se preservar a água. As respostas dos grupos demostraram que eles reconhecem a importância desse recurso para sobrevivência humana. Por exemplo, G2: "A água é essencial para nossa sobrevivência, temos menos de $1 \%$ de água doce para nosso consumo, essa quantidade é muito pequena por isso devemos economizar".

A última questão (Q5): "dê algumas sugestões para evitar o desperdício da água". Essa questão foi interessante porque gerou uma discussão entre os alunos, cada um falando o que fazia para economizar água. Dentre as sugestões apresentadas pelos grupos, destacamos: "Reutilizar a água da máquina de lavar roupas para lavar calçadas e dar descarga no vaso sanitário, fechar a torneira enquanto se escova os dentes, não demorar no banho, não lavar automóveis e calçadas com água de torneira, utilizar água da chuva para limpeza".

A resolução das questões permitiu observar o processo de aprendizagem dos estudantes, analisando seus questionamentos e intervenções. Nesse processo de interação por meio do diálogo, percebeu-se que houve apropriação de alguns conteúdos abordados e demonstração de atitude preventiva sobre a escassez da 
água e de como o ser humano pode colaborar para minimizar esse problema ambiental. Durante o desenvolvimento da atividade experimental, percebeu-se que os alunos se sentiram motivados a pesquisar, dialogar e discutir ideias. Isto pode indicar a contribuição de atividades experimentais associada à abordagem de temas sociocientíficos, como é o caso da Água, para a emergência do papel protagonista dos estudantes em sala de aula (MOREIRA; PEDRANCINI, 2016).

Em linhas gerais, percebeu-se a necessidade de um melhor entendimento conceitual acerca do termo contaminação, potabilidade e especificidade de cada etapa do tratamento de água. Todavia, a atividade experimental e a resolução das questões possibilitaram o trabalho em grupo e o desenvolvimento de habilidades, tais como: comunicação, cooperação, autonomia e respeito mútuo entre os alunos no processo de aprendizagem (SOUZA; DOURADO, 2015). Além disso, nessa atividade os alunos puderam desenvolver habilidades características do ensino por investigação (elaboração de hipóteses, proposição de experimentos, elaboração de conclusões e comunicação de resultados) segundo Suart (2008), Vieira (2012) e Carvalho (2013), com a mediação da professora a partir de questionamentos feitos no momento das aulas (CARVALHO, 2018).

\section{ANÁLISE DAS RESPOSTAS FINAIS DOS ALUNOS AOS PROBLEMAS (P1 E P2)}

A sistematização da sequência foi realizada com a reapresentação dos problemas para uma nova resolução pelos estudantes, com o objetivo de identificar se houve evolução nas suas respostas.

Sobre $\mathrm{P} 1,1$ o questionamento, nove alunos (90\%) expressaram respostas satisfatórias (RS), demonstrando compreender que a água recebida da torneira ainda pode está imprópria para consumo humano. Por exemplo, o aluno A2 respondeu da seguinte forma: "Não, porque até chegar às nossas casas a água passa por um longo caminho de canos e caixas d'água que podem estar sujos e contaminar a água. Por isso devemos fazer outros tratamentos como filtrar e ferver a água". Um aluno (10\%) não respondeu (NR).

Em relação ao 2ㅇ questionamento de $\mathrm{P} 1$, todos os alunos (100\%) apresentaram RS, afirmando que a aparência física não é suficiente para garantir a potabilidade da água, pois esta ainda pode conter impurezas que não são vistas a olho nu. Tais respostas refletem características macroscópicas e microscópicas da água. A título de ilustração, o aluno A5 respondeu: "não, a água potável deve ser incolor, inodora e insípida, ou seja, é preciso analisar cor, cheiro e sabor, porque mesmo parecendo está limpa ainda pode conter bactérias presentes".

No 1 o questionamento de P2, a análise mostrou que 8 alunos (80\%) expressaram (RS), apresentando a compreensão de que não basta apenas proibir de jogar lixo no rio, mas é necessário um tratamento de despoluição da água, campanhas de conscientização da população e tratamento dos esgotos descartados. Para ilustrar, o aluno A3 respondeu: "Faria uma limpeza no rio, proibia de jogar lixo e faria um tratamento da água para que ela voltasse a ser limpa". Dois alunos (20\%) expressaram (RI) como o aluno A8 que respondeu "Incentivaria as pessoas a não jogar lixo no rio".

Três alunos (30\%) apresentaram RS para o 2ㅇ questionamento de P2, considerando as propriedades da água. $\mathrm{O}$ aluno $\mathrm{A} 2$ respondeu: “Porque a água tem 
a capacidade de dissolver a maioria das substâncias, assim pode ficar contaminada facilmente". Seis alunos responderam que a água fica contaminada por causa da falta de consciência da população, que joga lixo e esgotos no rio. O aluno A5 respondeu: "Porque a população não cuida do meio ambiente e joga lixos e esgotos" (RI). Um aluno não respondeu esse questionamento (NR).

Quanto ao 3o questionamento do P2, todos os alunos expressaram RS, afirmando que a poluição do rio se deve ao fato da população jogar lixos e esgotos. O Aluno A2 respondeu: "Os lixos que as pessoas jogam e os esgotos das casas".

Em linhas gerais, alguns alunos apresentaram respostas mais simplificadas para alguns questionamentos. Entretanto, percebeu-se no decorrer do processo de análise das atividades realizadas na sequência, que as respostas e justificativas apresentadas pela maioria dos estudantes se mostraram mais embasadas no conhecimento científico escolar. Dessa forma, pode-se inferir que as atividades vivenciadas na sequência proporcionaram aos estudantes uma melhor compreensão dos conteúdos químicos associados à temática da Água.

\section{CONSIDERAÇÕES FINAIS}

Os resultados apontam que os alunos participaram da resolução de problemas por meio de ações direcionadas à elaboração de hipóteses; planejamento de experimento, discussão de ideias, comunicação de resultados e trabalho em grupo e autonomia, o que converge com as características e elementos do ensino por investigação citadas por Stuart (2008), Carvalho (2018) e Sasseron (2018). Houve um aumento do percentual das respostas satisfatórias para a resolução dos problemas, indicando uma maior aproximação do conhecimento assimilado pelo aluno com o conhecimento científico escolar. Inferimos que este aumento está relacionado às contribuições proporcionadas pelas atividades realizadas na sequência de forma articulada.

A análise das ações e interações dos estudantes nas atividades vivenciadas na sequência indicou a emergência das dimensões epistêmica e pedagógica no processo de ensino e aprendizagem. A abordagem conceitual no contexto da temática Água proporcionou a construção de sentidos e significados pelos alunos no processo de assimilação dos conteúdos de Ciências, especificamente em Matéria e suas Transformações, durante as ações realizadas nas a atividades da sequência. Os alunos atuaram como protagonistas no processo de aprendizagem, o professor e as atividades foram mediadores da construção do conhecimento em sala de aula, o que converge com finalidades da abordagem de resolução de problemas (CARVALHO, 2018).

A sequência sobre a temática Água propiciou a discussão e reflexão sobre a conscientização e responsabilidade com relação à qualidade e uso da água, contribuindo para a formação dos estudantes, a fim de que eles se tornem cidadãos engajados no uso sustentável da Água.

Por fim, os resultados mostram que a Resolução de Problemas vinculada ao ensino por investigação é uma abordagem didática eficiente, pois permite a contextualização e o desenvolvimento de ações e habilidades voltadas para realização de pequenas pesquisas no contexto escolar (SASSERON 2018; CARVALHO, 2018). 


\title{
Problem solving in science teaching based on an investigative approach
}

\begin{abstract}
This work is part of a broader academic master's research, whose objective is to analyze the potential of a didactic sequence on the theme Water elaborated based on the Problem Solving approach in the context of Research Education. The research was conducted in a 9th grade elementary school class from a public school in São Caetano, Pernambuco, in the discipline of Sciences. Data collection consisted of participant observation and student productions in solving problems and activities performed during sequence development. The data were analyzed based on the students' trajectory in the learning process and elements present in the teaching by investigation. The results indicate that the activities structured for the sequence provided the students with the process of knowledge search and the development of skills, such as hypothesis elaboration, experiment planning, discussion and communication of ideas, group work, autonomy and problem solving. . It is also important to identify the epistemic and pedagogical dimensions of knowledge during the actions developed by the students in the sequence activities. The approach of science contents in the context of the theme Water provided the construction of chemical concepts by the students, in a meaningful way, during the activities lived in the sequence.
\end{abstract}

KEYWORDS: Problem solving. Teaching by Investigation. Sciences. Elementary School II. Water. 


\section{REFERÊNCIAS}

ABREU, L. S. O desafio de formar professores dos anos iniciais do ensino fundamental para ensinar ciências. 2008. Dissertação (Mestrado). Salvador: Universidade Federal da Bahia estadual de Feira de Santana. 2008.

AMADO, M. V. Aprendizagem Baseada na Resolução de Problemas (ABRP) na Formação Contínua de Professores de Ciências. Interações, v. 11, p. 708-719, 2015.

AZEVEDO, M. C. P. S. Ensino por investigação: problematizando as atividades em sala de aula. In: CARVALHO, A. M. P. (Org.). Ensino de Ciências: unindo a pesquisa e a prática. São Paulo: Pioneira Thomson Learning, p. 19-33, 2004.

BATINGA, V. T. S. A resolução de problemas nas aulas de química: concepções de professores de química do ensino médio sobre problema e exercício. In: XV Encontro Nacional de Ensino de Química - XV ENEQ, 2004, Brasília. Anais [...] Brasília: XV ENEQ, 2010.

BATINGA, V. T. S.; TEIXEIRA, F. M. A Abordagem de Resolução de Problemas por uma professora de Química: Análise de um problema sobre a Combustão do Álcool envolvendo o conteúdo de Estequiometria. Revista Brasileira de Ensino de Ciência e Tecnologia. Ponta Grossa, v. 7, n. 1, p. 24-52, 2014.

BRASIL. Secretaria de Educação Fundamental. Parâmetros Curriculares Nacionais: Introdução e Ciências Naturais. Brasília: MEC/SEF, 1997.

BRASIL. Lei de Diretrizes e Bases da Educação Nacional. Brasília: 1996.

BRASIL. Guia de livros didáticos: PNLD 2011 - Ciências. Brasília: Ministério da Educação, Secretaria da Educação Básica, 2010.

BRASIL. Ministério da Educação. (1998). Parâmetros Curriculares Nacionais: Ciências Naturais. Secretaria de Educação Fundamental, Brasília, DF, 1998. Disponível em: http://portal.mec.gov.br/seb/arquivos/pdf/livro04.pdf. Acesso em: 27 de julho de 2017.

BRASIL. Ministério da Educação. Secretaria de Educação Fundamental. Parâmetros Curriculares Nacionais terceiro e quarto ciclos do ensino fundamental: Ciências Naturais, Brasília: MEC/SEF, 1998b.

CARVALHO, A. M. P. Ensino de ciências por investigação: condições para implementação em sala de aula. São Paulo: Cengage Learning, 2013. p. 1-20.

CARVALHO, A. M. P. Fundamentos Teóricos e Metodológicos do Ensino por Investigação. Revista Brasileira de Pesquisa em Educação em Ciências, 18, 3, p. 765-794, dez., 2018.

CHASSOT, A. (2003). Alfabetização científica: uma possibilidade para a inclusão social. Revista Brasileira de Educação, São Leopoldo, RS, 2005. Disponível em: 
http://www.scielo.br/pdf/rbedu/n22/n22a09.pdf. Acesso em: 27 de julho de 2017.

D'AMBRÓSIO, U. Algumas reflexões sobre a resolução de problemas. Disponível em http://issonaoeproblemaseu.blogspot.com/2010/09/algumas-reflexoessobre-resolucaode.html. Acesso em: 21 jul. 2017.

DIAS, P.F. O Tema Água no Ensino de Ciências: uma proposta didáticopedagógica elaborada com base nos três momentos pedagógicos. Disponível em:

https://repositorio.ufu.br/bitstream/123456789/17794/1/TemaAguaEnsino.pdf. Acesso em: 21 de nov. 2017.

GONÇALVES, Fábio Peres; GALIAZZI, Maria do Carmo. A natureza das atividades experimentais no ensino de ciências: um programa de pesquisa educativa nos cursos de licenciatura. In: MORAES, Roque; MANCUSO, Ronaldo (Orgs.).

Educação em ciências: produção de currículos e formação de professores. ljuí, Ed. Unijuí, 2004. p.237-252.

GOI, M. E. J.; SANTOS, F. M. T. "A construção do conhecimento químico por estratégias de resolução de problemas." IV Encontro Nacional de Pesquisa em Educação em Ciências (2003): 1-12.

GOZER, L.R. A água como tema de reflexão no Ensino de Química. Relato de uma experiência. Universidade Federal de Maringá, 2012. Disponível em: http://www.diaadiaeducacao.pr.gov.br/portals/cadernospde/pdebusca/produco es pde/2010/2010 uem qui artigo lourdes rodrigues gozer.pdf. Acesso em: 28. Nov. 2017.

GRAMOWSKI, V. B. et al. O livro didático: a fragmentação dos conteúdos das ciências Naturais. Revista da SBEnBIO- no 7. 2004. Disponível em: http://www.sbenbio.org.br/wordpress/wp-content/uploads/2014/11/R00111.pdf. Acesso em: 25 de nov. 2017.

KARAM, R. A. S.; PIETROCOLA, M. Habilidades Técnicas Versus Habilidades Estruturantes: Resolução de Problemas e o Papel da Matemática como Estruturante do Pensamento Físico. ALEXANDRIA Revista de Educação em Ciência e Tecnologia, v. 2, n. 2, p. 181-205, 2009.

KOBASHIGAWA, A. H. et.al. Estação ciência: formação de educadores para o ensino de ciências nas séries iniciais do ensino fundamental. In: IV Seminário Nacional ABC na Educação Científica. São Paulo, 2008. p. 212-217. Disponível em:

http://www.cienciamao.usp.br/dados/smm/ estacaocienciaformacaodeeducado resaraoensinodecienciasnasseriesiniciaisdoensinofundamental.trabalho.pdf. Acesso em: 06 de nov. 2017.

LEITE, L. \& ESTEVES, E. Ensino orientado para a Aprendizagem baseada na resolução de problemas na Licenciatura em ensino de Física e Química. 2005. 
LIMA, R. C. S. A. et al. A disciplina de Ciências na concepção dos alunos do $9^{\circ}$ ano da escola municipal Silvestre Fernandes Rocha, em Zé Doca (Ma). In: III Congresso Nacional de Educação. Anais [...]. Natal/RN, 2016. Disponível em: https://editorarealize.com.br/revistas/conedu/trabalhos/TRABALHO EV056 MD 1 SA18 ID10195 17082016103614.pdf. Acesso em: 20 de nov. 2017.

LOPES, J.B. Resolução de problemas em Física e Química: modelo para estratégias de ensino-aprendizagem. Lisboa: Texto Editora, 1994.

LÜDKE, M. e ANDRÉ, M. E. D. A. Pesquisa em educação: abordagens qualitativas. São Paulo: EPU, 1986.

MILARÉ, T.; ALVES FILHO, J. P. Ciências no nono ano do Ensino Fundamental: Da Disciplinaridade à Alfabetização Científica e Tecnológica. Revista Ensaio Belo Horizonte v. 12, n.02, p. 101-120, 2010.

MOREIRA, C.S e PEDRANCINI, V.D. Concepções iniciais dos alunos do oitavo ano do ensino fundamental sobre a fosfoetanolamina. V SINECT. Ponta Grossa-PR. 2016.

MORTIMER, E. F.; MACHADO, A. H.; ROMANELLI, L. I. A proposta curricular de Química do Estado de Minas Gerais: fundamentos e pressupostos. Química Nova, São Paulo, v. 23, n. 2, p. 273-283, 2000.

MUNFORD, D. e LIMA, M. E. C.C. Ensinar ciências por investigação: em quê estamos de acordo? Ensaio - Pesquisa em Educação em Ciências, Belo Horizonte, v. 9, n. 1, p. 72-89, 2007. Disponível em: http://www.portal.fae.ufmg.br/seer/index. php/ensaio/article/view/ 122/172. Acesso em: 27 nov. 2017.

OLIVEIRA, S. G. S. A alfabetização científica no ensino fundamental: desafios encontrados pelos docentes em escolas municipais de llhéus-Bahia. UESC, 2017.

POZO, J.(org). A Solução de Problemas: Aprender a resolver, resolver para aprender. Porto Alegre: Artmed, 1998.

POZO, J. I. (Org.); ANGÓN, Y. P. A solução de problemas como conteúdo procedimental da educação básica. In: A solução de problemas: Aprender a resolver, resolver para aprender. Porto Alegre: Artmed, 1998.

QUADROS, A. L. A Água como Tema Gerador do Conhecimento Químico. Química Nova na Escola, no 20, p.26-31, 2004.

SASSERON, L. H. Ensino de Ciências por Investigação e o Desenvolvimento de práticas: Uma Mirada para a Base Nacional Comum Curricular. Revista Brasileira de Pesquisa em Educação em Ciências, 18, 3, p. 1061-1085, dez., 2018.

SCHNETZLER, R. P.; ARAGÃO, R. M. R. Importância Sentido e Contribuições de Pesquisa para o Ensino de Química. Revista Química Nova na Escola, pesquisa 
SOLINO, A. P.; FERRAZ, A. T.; SASSERON, L. H. Ensino por investigação como abordagem didática: desenvolvimento de práticas científicas escolares. In: XXI Simpósio Nacional de Ensino de Física. Anais [...]. p. 1-6, 2015.

SOUSA, F. Ipojuca: "Água das raízes podres", ou o $3^{\circ}$ rio mais poluído do Brasil. Disponível em: https://ferdinandodesousa.wordpress.com/2017/09/21/ipojucaagua-das-raizes-podres-ou-o-3-rio-mais-poluido-do-brasil/. Acesso em: 04 de jan.2018.

SOUZA, S.C.; DOURADO, L. Aprendizagem Baseada em Problemas (ABP): Um Método de Aprendizagem Inovador para o Ensino Educativo. HOLOS. v.5. p.182200. 2015. Disponível em: http://www2.ifrn.edu.br/ojs/index.php/HOLOS/article. Acesso em: 12 de jul.2018.

SUART, R. C. Habilidades cognitivas manifestadas por alunos do ensino médio de química em atividades experimentais investigativas. (Dissertação Mestrado). Universidade de São Paulo, São Paulo, 2008.

TORRALBO, D. O Tema água no Ensino: A visão de Pesquisadores e de Professores de Química, 2009, 141f. Dissertação (Mestrado). Universidade de São Paulo, São Paulo, 2009.

VIEIRA, F. A. C. Ensino por Investigação e Aprendizagem Significativa Crítica: análise fenomenológica do potencial de uma proposta de ensino. 2012.149f. Tese (Doutorado)- Universidade Estadual Paulista. Faculdade de Ciências, Bauru, 2012.

VILELA, C. X, et al. Análise das concepções de alunos sobre aquecimento global em uma sequência didática elaborada a partir de uma situação-problema. XIV Encontro Nacional de Ensino de Química (XIV ENEQ). Anais [...]. Curitiba/PR 2008.

Recebido: 26 abr. 2019

Aprovado: 02 ago. 2019

DOI: 10.3895/actio.v4n2.9535

Como citar:

SILVA, E. T.; SÁ, R. A.; BATINGA, V. T. S. A resolução de problemas no ensino de Ciências baseada em uma abordagem investigativa. ACTIO, Curitiba, v. 4, n. 2, p. 169-188, mai./ago. 2019. Disponível em:

$<$ https://periodicos.utfpr.edu.br/actio>. Acesso em: XXX

Correspondência:

Elizete Terezinha da Silva

Rua do Dique, n² 235. Centro, São Caitano, Pernambuco, Brasil. CEP: 55130-000.

Direito autoral: Este artigo está licenciado sob os termos da Licença Creative Commons-Atribuição 4.0

Internacional.

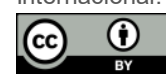

